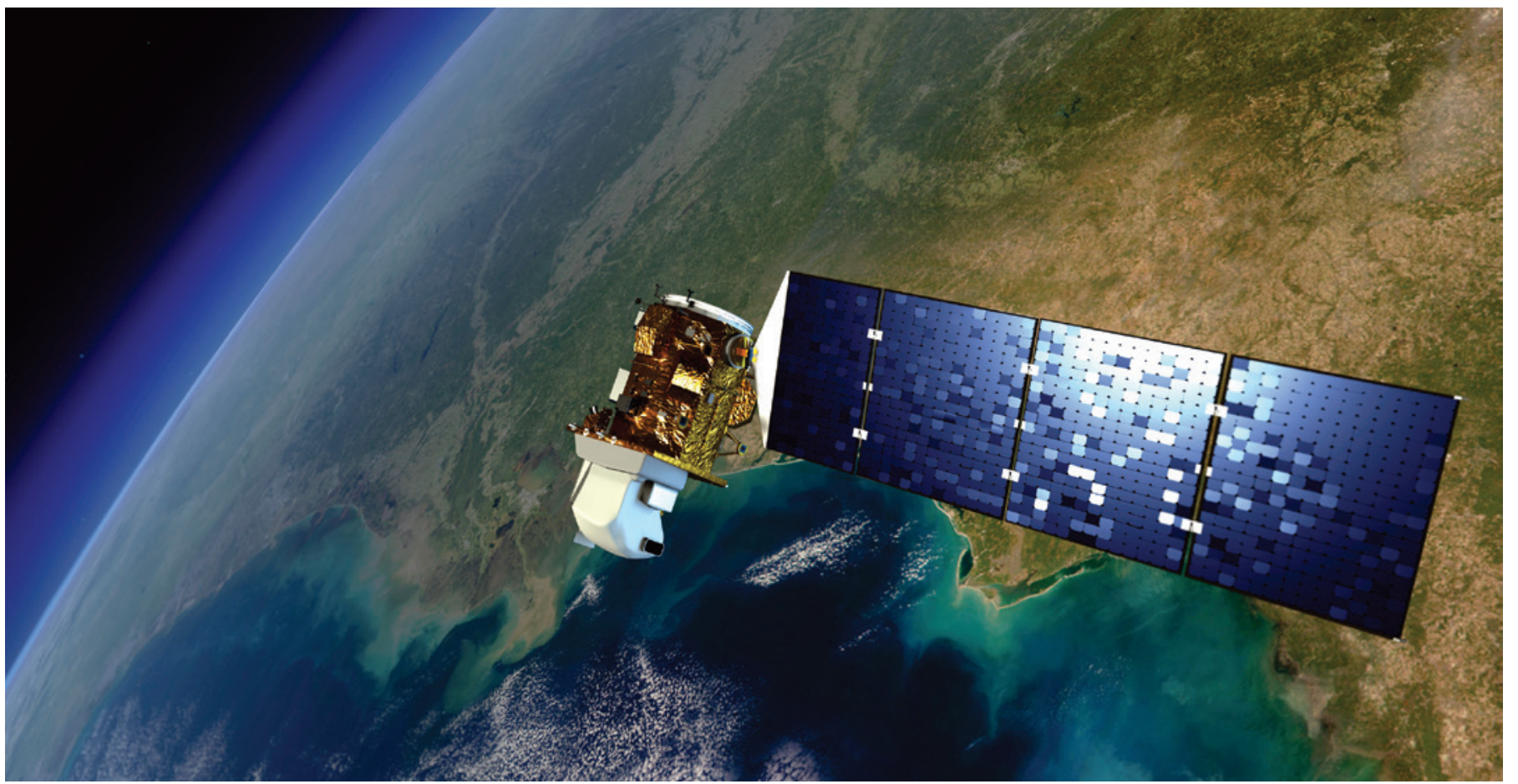

The Landsat 8 satellite launched in February 2013 (artist's impression).

\title{
Make Earth observations open access
}

\section{Freely available satellite imagery will improve science and environmental- monitoring products, say Michael A. Wulder and Nicholas C. Coops.}

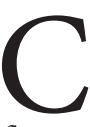

Thanges in land cover affect the global climate by absorbing and reflecting solar radiation, and by altering fluxes of heat, water vapour, carbon dioxide and other trace gases. Detailed assessments — regional, global, daily and seasonal — of land use and land cover are needed to monitor biodiversity loss and ecosystem dynamics and to aid in reducing emissions from deforestation and forest degradation ${ }^{1}$.

Satellite imagery is the best source of such data, especially over large areas. Observations need to be extensive, regular and consistent to establish baselines and trends. But today, most satellite observations have limited coverage and compatibility, because they are controlled by the diverse objectives of national space programmes. In many cases, satellite data are restricted or charged for.

A new era of open-access satellite data has arrived. In 2008, the US Geological Survey (USGS) released for free to the public its Landsat archive, which dates back to the 1970 s and is the world's largest collection of Earth imagery ${ }^{2}$. Greater computing power is also enabling scientists to manipulate big data representing larger areas and with greater sophistication, to produce multibillion-pixel composite maps of land cover and change across regions, continents and the globe. Monitoring land-cover change in near-real time is now a reality.

Obstacles remain. Data coverage in the Landsat archive is variable, in both space and time (see 'Global coverage'). And few people have enough computing power and bandwidth to download and manipulate the data. Decision-makers remain largely unaware of the vastly improved opportunities for environmental monitoring offered by the latest methods, and so are not yet using such data to their full potential.

Scientists and policy-makers can support the shift to open-access satellite data, and coordinate efforts to deliver the detailed global monitoring required by international climate change and emissions-reduction programmes. Further, governments should open up their national satellite image archives and integrate compatible data to fill gaps. And satellite imagery from future missions should be freely accessible to all to promote innovation and use.

Landsat is the longest-running civilian Earth-observing programme. The United States launched the first satellite in 1972, when public interest in space missions was high. In 1982, Landsat 4 began to deliver moredetailed imagery (with a spatial resolution of 30 metres, now considered a benchmark for historical analyses) and spectral channels at visible, near- and shortwave-infrared wavelengths, to track the unique signatures in reflected light of different types of vegetation.

The latest in the unbroken series of Landsat satellites is Landsat 8, launched in 2013, which measures Earth's surface with a resolution of 15-100 metres from visible to infrared wavelengths. Landsat data were archived from the outset, but early observing strategies and limitations to on-satellite storage and downlink capacity resulted in uneven global coverage.

Access policies have changed over the years. In the 1980s, Landsat observations 
were commercialized. Fewer images were acquired and prices rose, reaching thousands of dollars each ${ }^{3}$ and curtailing use. When Landsat 7 was launched in 1999, it collected images across the globe more systematically. Redistribution of purchased images became permissible, and users formed consortia to bulk buy and share raw images and products.

Usage rocketed in 2008, when Landsat made its images free. More than a million images were downloaded in the first year, compared with a previous annual high of about 25,000 images sold. More than 20 million images have been downloaded since the archive opened and the rate continues to increase.

\section{DATA REVOLUTION}

The mass of satellite data is fuelling a revolution in processing and analysis techniques. Cloud cover, the bane of optical remote sensing, can be overcome by building composite images. Over a period, clean pixels are selected, avoiding the requirement that entire images be clear. This approach is transforming continental and global-scale monitoring ${ }^{4}$.

Cycles of disturbance and growth can also be captured by tracing clean pixels through time. Landscape changes after a fire can be checked against expectations for vegetation recovery, for instance. And logical sequences - such as transitions from young forest to old - can be included with greater confidence in models and projections.

Advances in visualization and distributed cloud computing are also changing the game. For example, the powerful parallel processing facilities of the NASA Earth Exchange ${ }^{5}$ and the Google Earth Engine can handle large volumes of geospatial and remotely sensed data. Such central facilities allow users to bring algorithms to the large data sets while minimizing duplication of storage and processing efforts. Developing regions such as Africa, which lack computing power and infrastructure ${ }^{6}$, can also benefit from such shared platforms if they have the partnerships and bandwidth to access them.

When the archive was opened, there were more Landsat images outside it than in it. Many images were retained by the global network of receiving stations. An effort to consolidate these has added more than 3 million images to the repository since 2010; agreements are in place for a further 2 million to be ingested.

Future coverage should be much better. Landsat 8 can collect more than 700 images per day -14 times as much as in the 1980s. In April 2015, it should be joined by the first European Sentinel-2 satellite, which will map Earth's land area every 10 days. A second Sentinel-2 satellite is scheduled to be launched two years later. The three satellites together will image global land area twice a week.

Sentinel-2 also has a free and open data

\section{GLOBAL COVERAGE}

More than 120,000 Landsat images taken from December 2009 to November 2010 cover most of Earth's surface. On average, each $185 \times 185$-kilometre frame is imaged 21 times per year. But, irregular data receiving and uploads to the archive have resulted in patchy coverage. Current and future satellites will map the land more evenly.

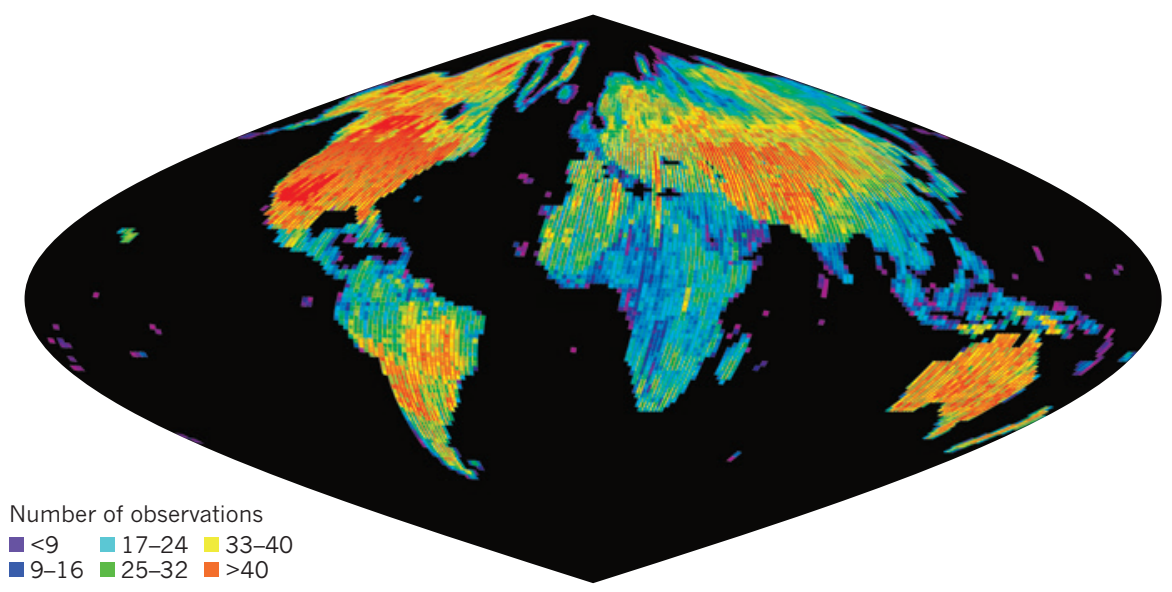

policy, although at present the data will be publicly available for only four months after collection. This strategy would limit access to wide timespans of data and could result in incomplete repositories and multiple versions of data with different calibrations.

\section{INTERNATIONAL STRATEGY}

Governments and the remote-sensing community should now seize the opportunity to develop a unified strategy for land monitoring.

First, as much historical imagery as possible should be deposited in the Landsat archive or an equivalent open repository. Leading Earth-observation nations ${ }^{7}$ whose satellites have sensors that complement Landsat should explore opportunities to add their data to the global pool. Second, the Earth-observing community and govern-

"Landsat 8 can collect more than 700 imagesper day - 14 times as much as in the 1980s" ments should commit to making future satellite programmes open access whenever possible. We urge the European Space Agency to consider ways to widen access to Sentinel-2's images. Alternative delivery mechanisms, such as a third-party archive and distribution site, could make data available to a broader array of users, allowing the intended science benefits to be reached.

Earth-observation projects need to become more like meteorological programmes, with standard imaging specifications and internationally agreed complementary satellite launches to ensure continuous coverage. The costs and difficulties in integrating national programmes for international benefit are significant. The benefits of open access demonstrated by the Landsat programme justify and encourage these efforts. We urge the Committee on Earth Observation Satellites interagency forum to continue facilitating communication between space agencies, commercial entities and scientific and operational data users towards establishing a more unified programme.

The remote-sensing community must advocate the development and maintenance of data archives and innovative processing methods. Best-practice approaches and standards can be developed by the Group on Earth Observations, a voluntary partnership between governments and international organizations to promote global collaboration around Earth observations, and offshoots such as the Global Forest Observation Initiative. To facilitate the use of data from differing sensors, scientists and data distribution centres should offer users calibrated data in widely compatible, analysis-ready formats.

Finally, researchers, policy-makers, nongovernmental organizations and land managers need to use and promote more widely the capacity of the satellite archives for capturing and characterizing past and present changes in land cover and land use.

Michael A. Wulder is a senior research scientist at the Canadian Forest Service, Natural Resources Canada, Victoria, Canada. Nicholas C. Coops is professor of remote sensing at the Faculty of Forest Resources Management, University of British Columbia, Vancouver, Canada. e-mail:mike.wulder@nrcan-rncan.gc.ca

1. Phelps, J., Webb, E. L. \& Adams, W. M. Nature Clim. Change 2, 497-503 (2012).

2. Woodcock, C. E. et al. Science 320, 1011 (2008),

3. Wulder, M. A., Masek, J. G., Cohen, W. B.,

Loveland, T. R. \& Woodcock, C. E. Remote Sens. Environ. 122, 2-10 (2012).

4. Hansen, M. C. \& Loveland, T. R. Remote Sens. Environ. 122, 66-74 (2012)

5. Nemani, R., Votava, P., Michaelis, A., Melton, F. \& Milesi, C. EOS 92, 109-110 (2011)

6. Roy, D. P., Ju, J., Mbow, C., Frost, P. \& Loveland, T. Remote Sens. Lett. 1, 111-117 (2010).

7. Belward, A. S. \& Skøien, J. O. ISPRS J. Photogramm. Remote Sens. http://dx.doi. org/10.1016/j.isprsjprs.2014.03.009 (2014). 